03.4

\title{
Самопроизвольное (спонтанное) вскипание затопленных струй, генерируемых при коллапсе паровых пузырьков
}

\author{
(ㄱ Т.П. Адамова ${ }^{1,2}$, В.М. Чудновский ${ }^{1}$, Д.С. Елистратов ${ }^{1,3}$ \\ ${ }^{1}$ Новосибирский государственный университет, Новосибирск, Россия \\ ${ }^{2}$ Институт неорганической химии им. А.В. Николаева СО РАН, Новосибирск, Россия \\ ${ }^{3}$ Институт теплофизики им. С.С. Кутателадзе СО РАН, Новосибирск, Россия \\ E-mail: t.adamova@nsu.ru
}

Поступило в Редакцию 12 августа 2021 г.

В окончательной редакции 20 сентября 2021 г.

Принято к публикации 20 сентября 2021 г.

\begin{abstract}
Экспериментально обнаружен эффект вторичного спонтанного вскипания затопленных струй, образующихся при коллапсе паровых пузырьков в процессе объемного кипения воды, недогретой до температуры насыщения, на торце лазерного оптоволокна.
\end{abstract}

Ключевые слова: затопленная струя, кипение недогретой жидкости, лазер.

DOI: 10.21883/PJTF.2022.01.51873.18991

Неравновесные кавитационные сферически-симметричные пузырьки при схлопывании сжимаются до минимальных размеров и, если не разрушаются, вновь воспроизводят себя, совершая последовательно несколько циклов затухающих колебаний [1]. Это явление хорошо известно под названием „отскок“ $[1,2]$. Однако если форма неравновесного кавитационного пузырька не является сферически-симметричной, то коллапс таких пузырьков может привести к их распаду, при котором вместо „отскока“ наблюдается затопленная кумулятивная струя [3-12]. Эти струи, несмотря на их скромные размеры, локально могут создавать гигантские гидродинамические давления за счет своей высокой скорости. Такие струи представляют значительный практический интерес в различных направлениях, например в промышленной химии для селективной очистки поверхностей, а также в медицине для атравматичного санирования тканевых покровов или при хирургических вмешательствах, в том числе и при передаче тепла $[3,12,13]$. Нагретыми струи могут оказаться, когда образуются при коллапсе паровых пузырьков, возникших в результате кипения недогретой жидкости $[11,12]$.

Кипение недогретой жидкости можно наблюдать при закаливании раскаленного металла в холодной воде или в начальные моменты вскипания воды в чайнике. При кипении такой жидкости паровые пузырьки растут и сразу же схлопываются, поскольку при соприкосновении с холодной жидкостью пар в пузырьке начинает конденсироваться [14]. В условиях, когда недогрев жидкости большой, коллапс пузырьков вблизи сосредоточенного нагревателя приводит к образованию разогретых затопленных струй с температурой, близкой к температуре кипения $[3,11,12]$. Возможна ситуация, когда разогретая струя, движущаяся с большой скоростью через окружающую ее холодную (недогретую) жидкость, вновь закипит. Подобное самопроизвольное вторичное вскипание мо- жет произойти из-за понижения давления в движущейся жидкости согласно закону Бернулли. В этом случае снизится и температура кипения нагретой жидкости. Таким образом, при достаточно большой скорости струи возможен „отскок“ в виде воспроизводства кипения. Данное явление подобно явлению вскипания разогретой движущейся жидкости на изгибах труб.

В настоящей работе сообщается об экспериментальном наблюдении явления спонтанного вторичного вскипания в кумулятивной струе, образующейся при коллапсе парового пузырька на лазерном нагревательном элементе.

В экспериментах использовался полупроводниковый лазер с длиной волны излучения $1.94 \mu \mathrm{m}$, излучение которого проводилось по кварц-кварцевому полимерному волокну диаметром $600 \mu \mathrm{m}$. Излучение с длиной волны $1.94 \mu \mathrm{m}$ очень сильно поглощается в воде с коэффициентом поглощения $\sim 100 \mathrm{~cm}^{-1}$, что позволяет инициировать вблизи торца оптоволокна объемное вскипание жидкости. Все эксперименты проводились на дистиллированной воде при температуре $30^{\circ} \mathrm{C}$ в кювете размером $16.5 \times 37 \times 20$ mm с использованием скоростной видеокамеры Photron FASTCAM Mini UX100 со скоростью съемки до $100000 \mathrm{fps}$. Исследовался элементарный акт вскипания - рост и схлопывание одиночного пузырька.

На рис. 1 показано формирование и развитие парового пузырька в процессе объемного вскипания недогретой воды перед торцом оптоволокна. В период роста пузырек охватывает кончик оптоволокна и после достижения максимального размера начинает схлопываться. Коллапс пузырька на торце оптоволокна приводит к потере его сферичности, поскольку массы жидкости, двигавшиеся изначально к центру пузыря, вынуждены обтекать так называемый „обратный уступ“. Радиальные потоки устремляются навстречу друг другу, пузырек при этом сжимается, как показано на кадре 8 (рис. 1) и 


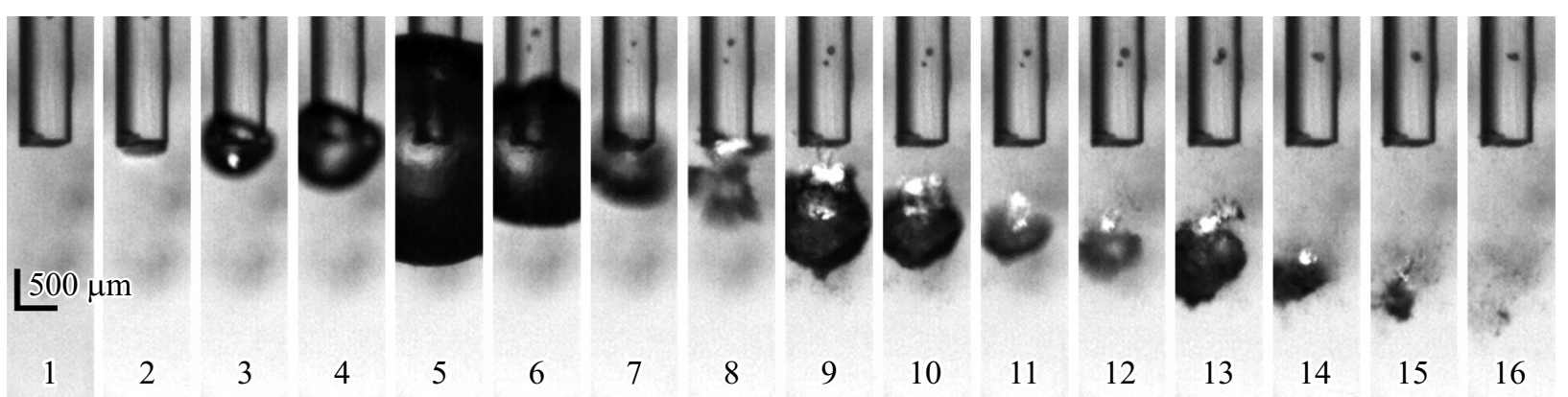

Рис. 1. Формирование и развитие парового пузырька при вскипании недогретой дистиллированной воды под действием непрерывного лазерного излучения с длиной волны $1.94 \mu \mathrm{m}$ и мощностью $10 \mathrm{~W}$. Диаметр оптоволокна $600 \mu \mathrm{m}$. Цифрами обозначены номера кадров. Средний интервал между кадрами $0.04 \mathrm{~ms}$.

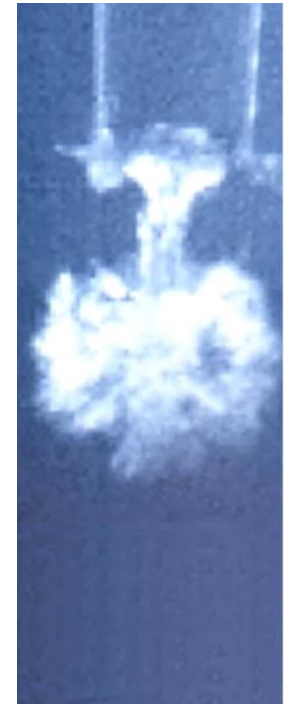

1

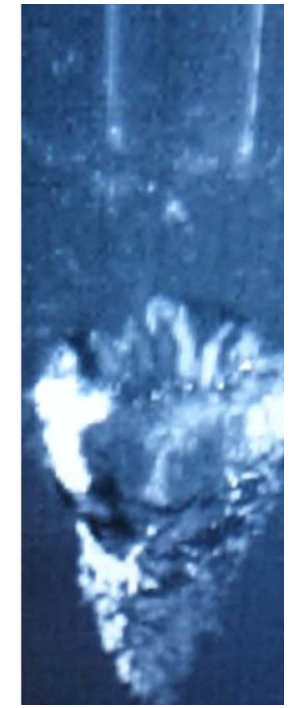

2

Рис. 2. Начало процесса вторичного вскипания воды вблизи торца оптоволокна (кадр 1) и интенсивное кипение жидкости в затопленной струе, движущейся от торца оптоволокна (кадр 2). Интервал между кадрами $0.04 \mathrm{~ms}$.

кадре 1 (рис. 2). Затем радиальные потоки сталкиваются и трансформируются в аксиальные струи, направленные в противоположные стороны: к торцу и от торца оптоволокна. Струя, направленная к торцу, сталкивается с его поверхностью, тогда как струя, направленная от торца, формирует затопленную кумулятивную струю, распространяющуюся в глубь жидкости (кадры 9-11 на рис. 1) [11].

Образованные струи являются нагретыми, так как вблизи границы раздела фаз вода нагрета и первой входит в формирующийся поток. Нагретая вода может образовываться как вследствие конденсации пара, так и в результате того, что часть воды, нагретая лазерным излучением, не испарилась, а осталась в жидком состоянии на границе пузырька. При схлопывании пузырька

эти слои в первую очередь будут вовлечены в струйное течение [12].

Как видно из рис. 1, струя жидкости в изучаемых условиях инициирует процесс вторичного вскипания. Кадр 8 на рис. 1 и кадр 1 на рис. 2 демонстрируют начало вскипания жидкости, а кадры 9-15 (рис. 1) и кадр 2 (рис. 2) - типичную картину кипения движущейся жидкости. Определяемая на кадрах 8 и 9 (рис. 1) и кадре 1 (рис. 2) перемычка, вероятно, также представляет собой вскипевшую в струйном потоке жидкость. Видно, что вторичный, вновь образованный пузырек (кадр 2 на рис. 2) частично состоит из множества мелких пузырьков. При коллапсе вторичного пузырька также образуются противоположно направленные затопленные струи, которые могут складываться с первоначальными, формируя поток нагретой жидкости.

Скорость струи сильно зависит от расстояния относительно торца оптоволокна. В начальный момент времени ее значение $\sim 27 \pm 1 \mathrm{~m} / \mathrm{s}$. Если оценить падение давления в струе по закону Бернулли, то давление получается отрицательным ( 2.5 atm). Очевидно, закон Бернулли для оценки падения давления в струе в данной задаче можно использовать только в качестве нулевого приближения, но с уверенностью можно сказать, что давление понижается настолько, что вскипание воды происходит при температурах, существенно меньших $100^{\circ} \mathrm{C}$.

Дополнительной причиной снижения давления в нагретой затопленной струе, приводящей к ее вскипанию, могут служить акустические волны, генерируемые при коллапсе парового пузырька. Исследование таких волн проведено в работе [15]. Были зарегистрированы волны с амплитудой более $12 \mathrm{~atm}$. Анализ результатов этой работы показывает, что если бы среда была неограниченной, то вклад акустических волн в механизм спонтанного вскипания разогретых затопленных струй был бы несуществен. Однако в проведенных экспериментах волны давления отражались от стенок и, возвращаясь, могли оказывать влияние на коллапс пузырька. Но для подтверждения данной гипотезы требуются детальные численные расчеты. 


\section{Благодарности}

Авторы выражают глубокую благодарность В.А. Буланову за полезную дискуссию и обсуждение результатов.

\section{Финансирование работы}

Работа выполнена при поддержке Российского научного фонда (проект № 19-19-00122).

\section{Конфликт интересов}

Авторы заявляют, что у них нет конфликта интересов.

\section{Список литературы}

[1] В.В. Рождественский, Кавитация (Судостроение, Л., 1977).

[2] Б.М. Дорофеев, Теплофизика высоких температур, 23 (3), 586 (1985). [B.M. Dorofeev, High Temp., 23 (3), 479 (1985).].

[3] В.М. Чудновский, В.И. Юсупов, Письма в ЖТФ, 46 (20), 31 (2020). DOI: 10.21883/PJTF.2020.20.50153.18426 [V.M. Chudnovskii, V.I. Yusupov, Tech. Phys. Lett., 46 (10), 1024 (2020). DOI: 10.1134/S1063785020100211].

[4] A. Vogel, V. Venugopalan, Chem. Rev., 103 (2), 577 (2003). DOI: $10.1021 / \mathrm{cr} 010379 \mathrm{n}$

[5] V. Robles, E. Gutierrez-Herrera, L.F. Devia-Cruz, D. Banks, S. Camacho-Lopez, G. Aguilar, Phys. Fluids, 32 (4), 042005 (2020). DOI: $10.1063 / 5.0007164$

[6] R. Dijkink, S. Le Gac, E. Nijhuis, A. van den Berg, I. Vermes, A. Poot, C.-D. Ohl, Phys. Med. Biol., 53 (2), 375 (2008). DOI: $10.1088 / 0031-9155 / 53 / 2 / 006$

[7] S.D. George, S. Chidangil, D. Mathur, Langmuir, 35 (31), 010139 (2019). DOI: 10.1021/acs.langmuir.8b03293

[8] K.F. Chan, T.J. Pfefer, J.M.H. Teichman, A.J. Welch, J. Endourology, 15 (3), 257 (2001). DOI: $10.1089 / 089277901750161737$

[9] В.П. Минаев, Н.В. Минаев, В.И. Юсупов, А.М. Дымов, Н.И. Сорокин, В.Ю. Лекарев, А.3. Винаров, Л.М. Рапопорт, Квантовая электроника, 49 (4), 404 (2019). [V.P. Minaev, N.V. Minaev, V.I. Yusupov, A.M. Dymov, N.I. Sorokin, V.Yu. Lekarev, A.Z. Vinarov, L.M. Rapoport, Quantum Electron., 49 (4), 404 (2019). DOI: 10.1070/QEL16809].

[10] Ф.В. Бункин, М.И. Трибельский, УФН, 130 (2), 193 (1980). DOI: 10.3367/UFNr.0130.198002a.0193 [F.V. Bunkin, M.I. Tribel'skii, Phys. Usp., 23 (2), 105 (1980). DOI: 10.1070/PU1980v023n02ABEH004904].

[11] V.M. Chudnovskii, A.A. Levin, V.I. Yusupov, M.A. Guzev, A.A. Chernov, Int. J. Heat Mass Transfer, 150, 119286 (2020). DOI: 10.1016/j.ijheatmasstransfer.2019.119286

[12] R.V. Fursenko, V.M. Chudnovskii, S.S. Minaev, J. Okajima, Int. J. Heat Mass Transfer, 163, 120420 (2020). DOI: $10.1016 /$ j.ijheatmasstransfer.2020.120420

[13] C.-D. Ohl, M. Arora, R. Dijkink, V. Janve, D. Lohse, Appl. Phys. Lett., 89 (7), 074102 (2006). DOI: 10.1063/1.2337506

[14] A.A. Chernov, A.A. Pil'nik, I.V. Vladyko, S.I. Lezhnin, Sci. Rep., 10 (1), 16526 (2020).
[15] В.И. Юсупов, А.Н. Коновалов, В.А. Ульянов, В.Н. Баграташвили, Акуст. журн., 62 (5), 531 (2016). DOI: $10.7868 / \mathrm{S} 0320791916050191 \quad$ [V.I. Yusupov, A.N. Konovalov, V.A. Ul'yanov, V.N. Bagratashvili, Acoust. Phys., 62, (5), 537 (2016). DOI: $10.1134 / \mathrm{S} 1063771016050183]$. 